\title{
Radioactivity and Radionuclide Distribution in Jabel Bawr Oil Site of Kirkuk-Iraq
}

\author{
Ali H. Taqi* and Berivan F. Namq
}

Department of Physics, College of Science, Kirkuk University, Kirkuk, Iraq

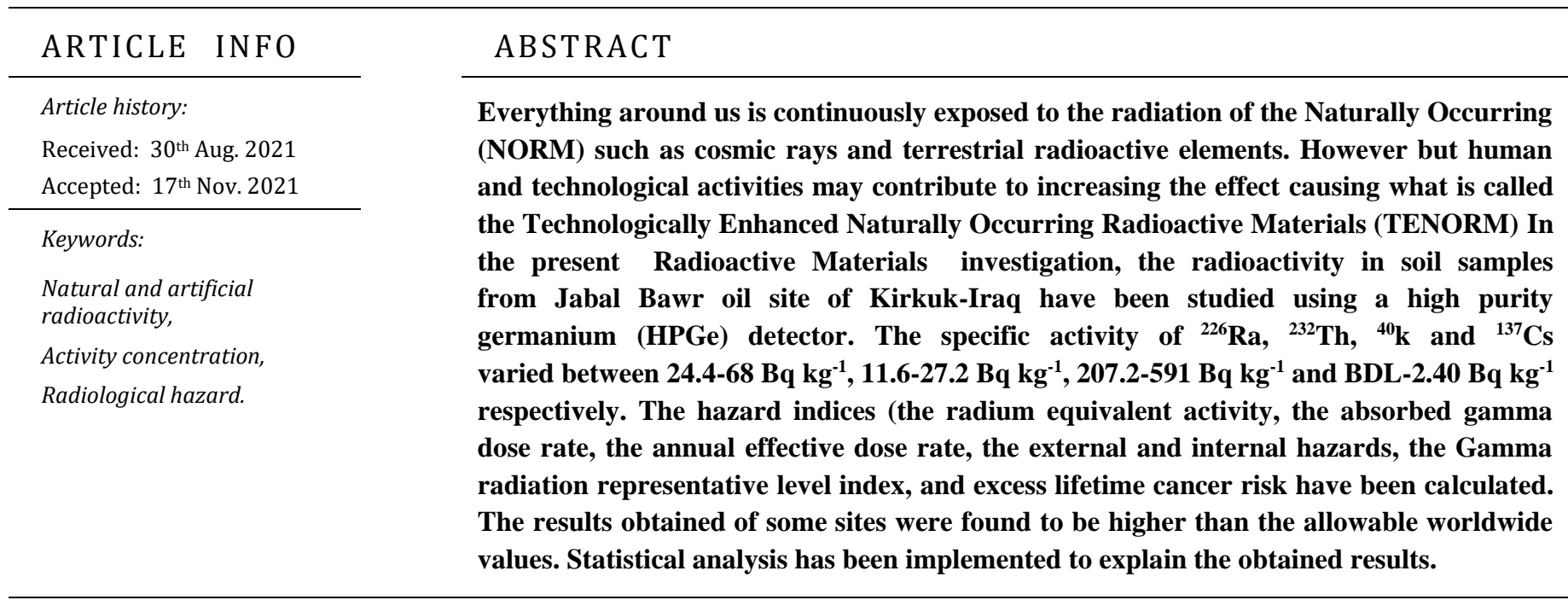

\section{INTRODUCTION}

Naturally Occurring Radioactive Materials (NORM) have been found in the soil, rocks, water, and building materials. Radionuclides such as ${ }^{238} \mathrm{U}$ and ${ }^{232} \mathrm{Th}$ or their progeny, as well as ${ }^{40} \mathrm{~K}$, can be traced back to the prehistoric era [1]. It is unavoidable for humans to be exposed to ionising radiation. External radiation exposure is caused by both natural and man-made radioactivity. Ionizing radiation interacts with the human body, causing a variety of biological effects that may manifest as clinical symptoms [2].

Measurements of soil radioactivity levels are important for understanding changes in the natural radiation background as a function of geographical location and time, and also in forming the basis for the assessment of the degree of the radioactive contamination or pollution in the environment in the future $[3,4]$.

The current study aims at evaluate the specific activity of ${ }^{226} \mathrm{Ra},{ }^{232} \mathrm{Th},{ }^{40} \mathrm{~K}$ and ${ }^{137} \mathrm{Cs}$ in soil samples collected from Jable Bawr oil site of Kirkuk-Iraq . The hazard indices: the radium equivalent activity $\left(\mathrm{Ra}_{\mathrm{eq}}\right)$, the absorbed dose (D), Gamma radiation representative level index $\left(\mathrm{I}_{\gamma}\right)$, the external hazard and internal hazard index $\left(H_{\mathrm{ex}}, \mathrm{H}_{\mathrm{in}}\right)$, the annual effective dose rate (AEDE), and excess lifetime cancer risk (ELCR) have also been calculated. Statistical analysis has been also implemented to explain the obtained results.

\section{EXPERIMENTAL TECHNIQUES}

In the present study, soil samples were selected from Jabel Bawr oil field of Kirkuk-Iraq which is distributed around oil wells. The locations of the investigated samples are shown in Fig. (1). The samples were taken at the chosen point from a depth of $45 \mathrm{~cm}$ labelled, then mixed, sieved through $0.25-\mathrm{mm}$ mesh, dried at $100{ }^{\circ} \mathrm{C}$ for 24 hours, placed in polyethylene containers, and finally were stored at least 4 weeks to ensure the radioactive equilibrium between radon and its decay products [5].

The acquisition time of each sample was $3600 \mathrm{sec}$ in the gamma energy transition rang $\sim 1000 \mathrm{keV}-2614 \mathrm{keV}$ which is performed using a high-purity germanium (HPGe) detector and spectroscopy system. The specific activities of the $232 \mathrm{Th}$ was determined using gamma-ray transition lines of $228 \mathrm{Ac}$ and $212 \mathrm{~Pb}$, while the specific activity of $226 \mathrm{Ra}$ and $214 \mathrm{~Pb}$ were used to determine the activity of $238 \mathrm{U}$, gamma transition peaks of $40 \mathrm{~K}$ and $137 \mathrm{Cs}$ were determined at 1461 and $662 \mathrm{keV}$, respectively. 


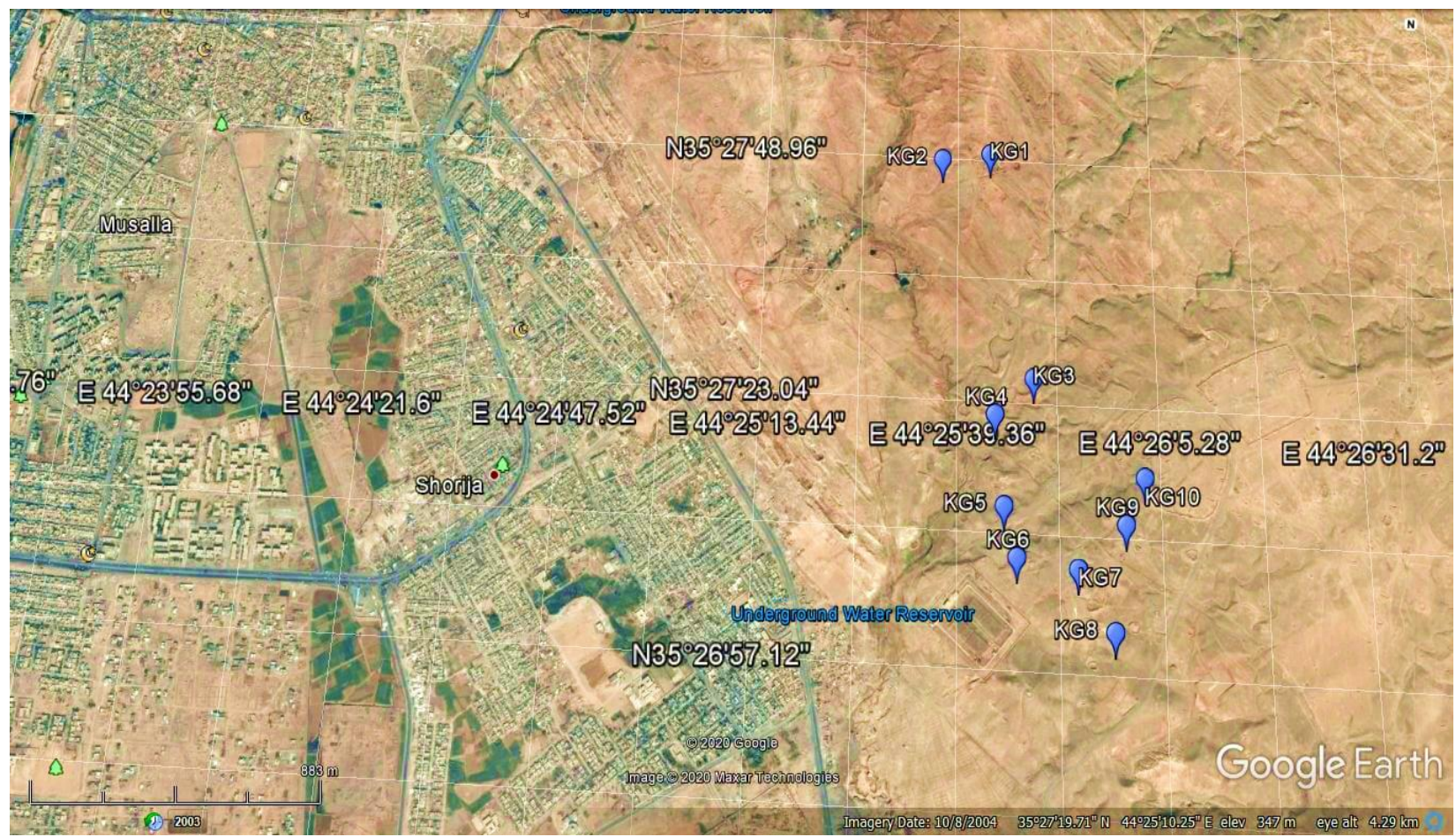

Fig. (1): Locations of the investigated samples

\section{Estimation of activity and hazard indices}

The specific activity of the investigated samples is obtained using the following equation [6]:

$$
A\left(B \mathrm{qg}^{-1}\right)=\frac{C_{n e t}}{\varepsilon\left(E_{\gamma}\right) \times I_{\gamma} \times m(\mathrm{~kg})}
$$

Where $C_{n e t}$ is the net peak count rate (Count $\left.\mathrm{Sec}^{-1}\right), \mathrm{I}_{\gamma}$ is the probability of the emission of the gamma line corresponding to the peak energy, $\varepsilon$ is the absolute efficiency at photo peak energy.

The Radium activity equivalent $\left(\mathrm{Ra}_{\mathrm{eq}}\right)$ is widely used to determine the hazards index in terms of the activities of the ${ }^{226} \mathrm{Ra},{ }^{232} \mathrm{Th}$ and ${ }^{40} \mathrm{~K}$ as explained by the following[7]:

$$
R a_{e q}=A_{R a}+1.43 A_{T h}+0.077 A_{k}
$$

The absorbed dose rate (D) in $\mathrm{nGy} \mathrm{h}^{-1}$ can be determined using the following relation [8-10]:

$$
D=0.462 A_{R a}+0.604 A_{T h}+0.0417 A_{K}
$$

The external and internal hazard indices $\left(\mathrm{H}_{\mathrm{ex}}\right.$ and $\left.\mathrm{H}_{\mathrm{in}}\right)$ were measured by the following equation [11]:

$$
H_{e x}=\frac{A_{R a}}{370}+\frac{A_{T h}}{259}+\frac{A_{K}}{4810} \leq 1
$$

$$
H_{\text {in }}=\frac{A_{R a}}{185}+\frac{A_{T h}}{259}+\frac{A_{K}}{4810} \leq 1
$$

The representative level index (I $\gamma$ ) is used for measuring gamma radiation in soil correlated with the natural radionuclide. This is defined by the following[12]:

$$
I_{\gamma}=\frac{A_{R a}}{150}+\frac{A_{T h}}{100}+\frac{A_{K}}{1500} \leq 1
$$

In order to calculate the annual effective dose equivalent at air, the outdoor occupancy factor of about 0.2 and the conversion coefficient of $0.7 \mathrm{~Sv} \mathrm{~Gy}^{-1}$ which is used to convert the absorbed dose rate (D) in air (in $\left.\mathrm{nGy} \mathrm{h}^{-1}\right)$ to the effective dose equivalent in $\left(\mathrm{Sv} \mathrm{y}^{-1}\right)$ obtained by adults (female and male) must be taken into consideration. The average annual mean effective dose worldwide is $460 \mu \mathrm{Sv} \mathrm{y}^{-1}$ [10]. AEDE in $\mathrm{mSv}^{-1}$ is computed by the following equations:

$$
\begin{aligned}
& A E D E_{\text {out }}=D \times 8760 \times 0.2 \times 0.7 \times 10^{-6} \\
& A E D E_{\text {in }}=D \times 8760 \times 0.8 \times 0.7 \times 10^{-6}
\end{aligned}
$$

The excess lifetime cancer risk (ELCR) is caused by ionising radiation exposure over a lifetime [13, 14]:

$$
E L C R=A E D E \times D L \times R F
$$


Where DL is the average life span (70 years) and RF $\left(\mathrm{Sv}^{-1}\right)$ fatal risk factor per Sievert, which is 0.057 as per the International Commission on Radiological Protection[15].

\section{RESULTS AND DISCUSSION}

\subsection{Specific activity hazard indices}

The specific activity of ${ }^{226} \mathrm{Ra}$ (series of ${ }^{238} \mathrm{U}$ ), ${ }^{228} \mathrm{Ac}$ (series of ${ }^{232} \mathrm{Th}$ ), non-series $\left({ }^{40} \mathrm{~K}\right)$ and ${ }^{137} \mathrm{Cs}$ of the investigated 10 soil samples are depicted in Figs (2 to 4 respectively). Table (1). shows the specific activity and average values of ${ }^{226} \mathrm{Ra},{ }^{232} \mathrm{Th},{ }^{40} \mathrm{~K}$ and ${ }^{137} \mathrm{Cs}$.

The range of the specific activity of ${ }^{226} \mathrm{Ra}$ was 24.4-68 Bq kg-1 with an average of $46.30 \mathrm{~Bq} \mathrm{~kg}^{-1}$. The minimum value is obtained in KG1 and the maximum value is obtained in KG4. The higher values were for the sites closest to the oil wells. In general, the geochemical composition and origin of the soil types are also attributable to the radioactivity. The range of the measured specific activity of ${ }^{232} \mathrm{Th}$ was $11.6-27.2 \mathrm{~Bq} \mathrm{~kg}$ ${ }^{1}$ with an average of $22.10 \mathrm{~Bq} \mathrm{~kg}^{-1}$. The minimum value is obtained in KG9 and the maximum value is obtained in KG5 and KG10. The differences were significant in all samples depending on the distance from the oil wells. The specific activity of ${ }^{40} \mathrm{~K}$ was $207.2-591 \mathrm{~Bq} \mathrm{~kg}^{-1}$ with an average $387.07 \mathrm{~Bq} \mathrm{~kg}$. The minimum value is obtained in KG7 and the maximum value is obtained in KG10. The difference are also attributable to the soil type differences in the region under investigation value besides the industrial oil waste. In addition, contour maps of the specific activity are presented in Figs. (5, 6 and 7).

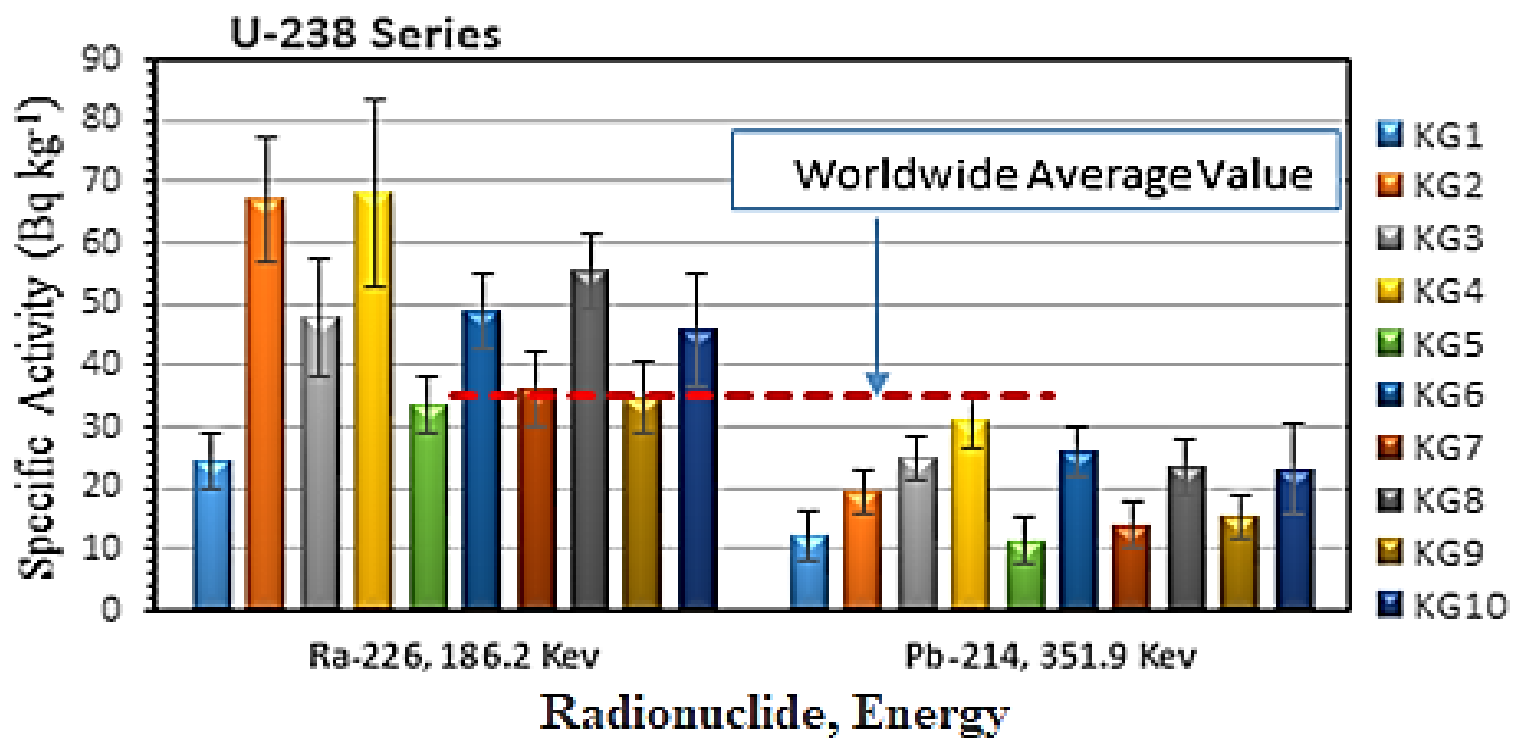

Fig. (2): specific activity of ${ }^{238}$ Useries of the investigated soil samples in comparison with the worldwide average value

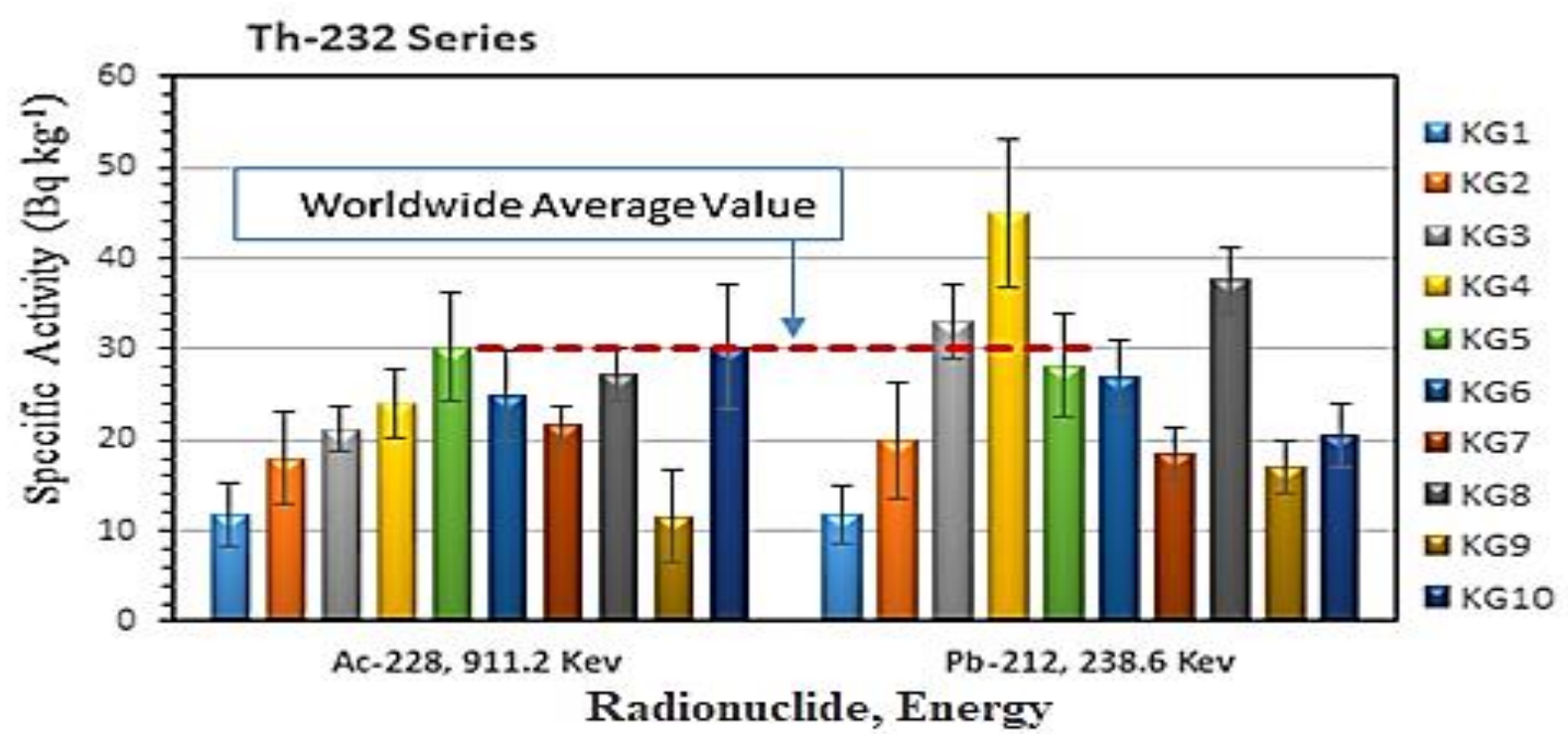

Fig. (3): specific activity of ${ }^{232} \mathrm{Th}$ series of the investigated soil samples in comparison with the worldwide average value 


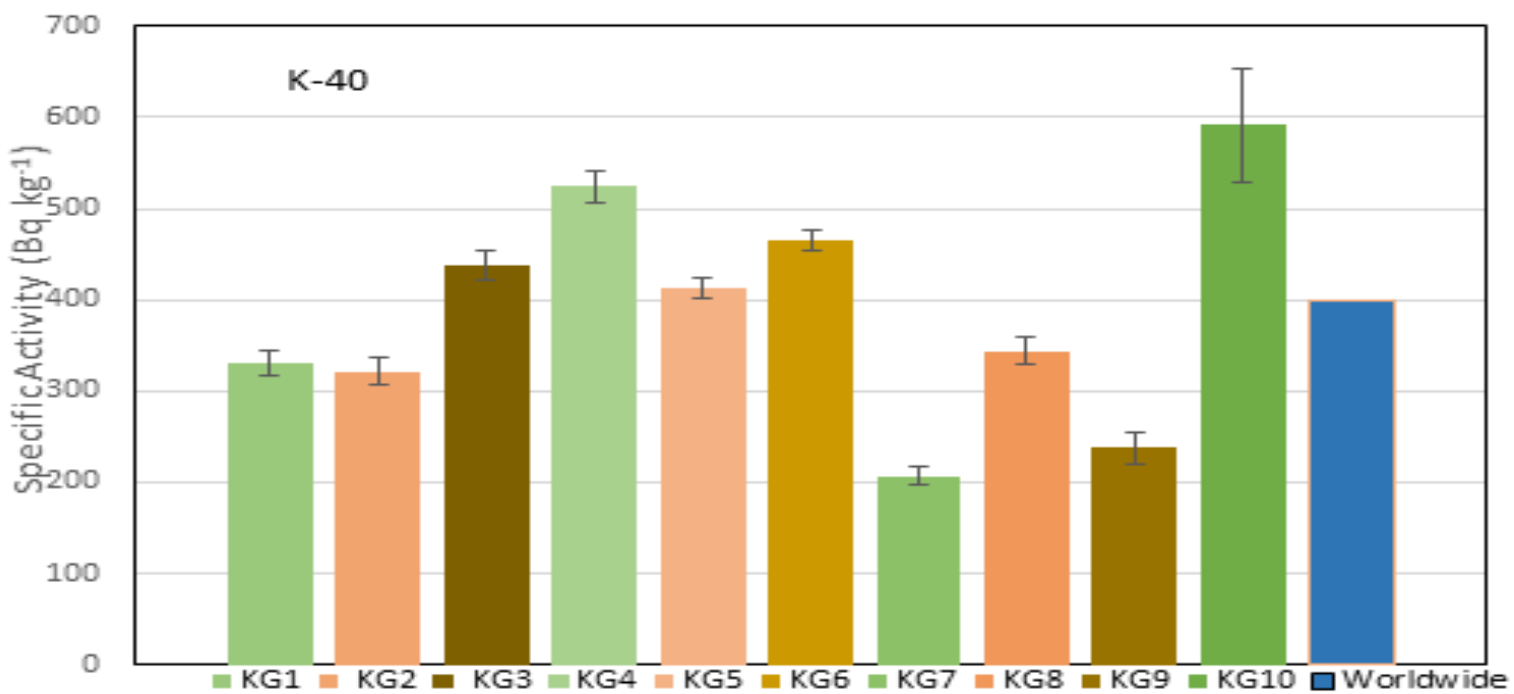

Fig. (4): specific activity of ${ }^{40} \mathrm{~K}$ series of the investigated soil samples in comparison with the worldwide average value

Table (1): Specific activity (Bq kg-1) of the selected samples of Jabel Bawr field. BDL: Below Detection Limit.

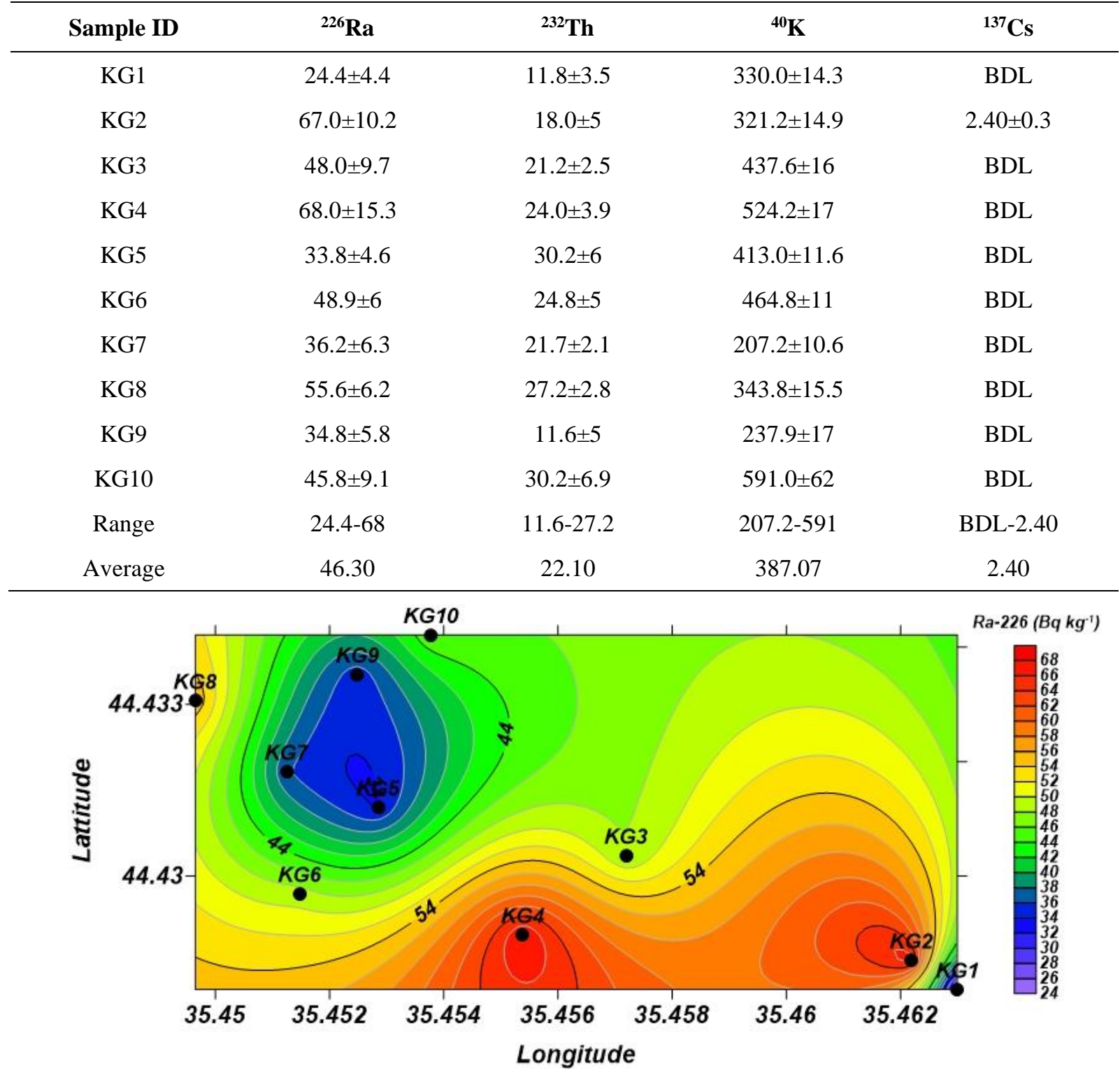

Fig. (5): a contour map of the sample locations and how the specific activity of ${ }^{226}$ Ra are distributed 


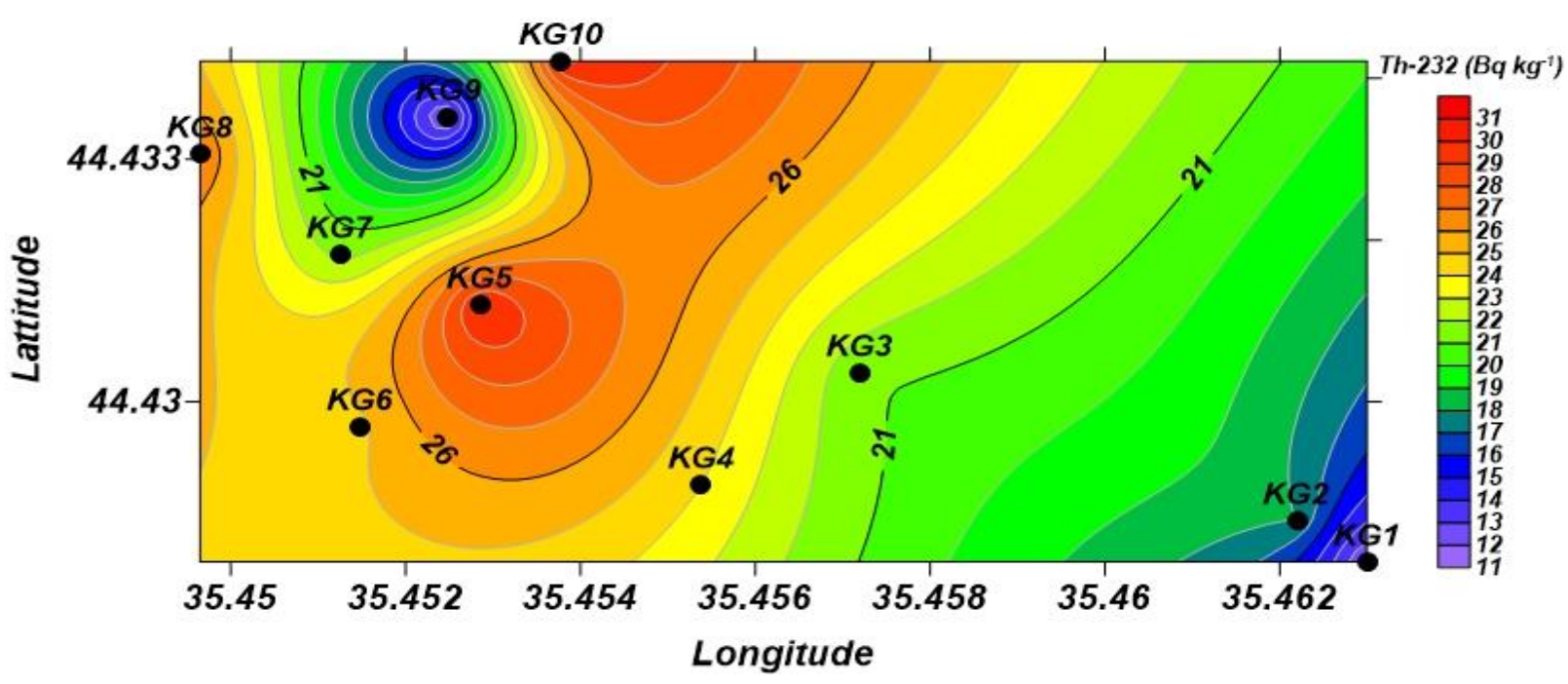

Fig. (6): a contour map of the sample locations and how specific activity of the ${ }^{232}$ Th are distributed

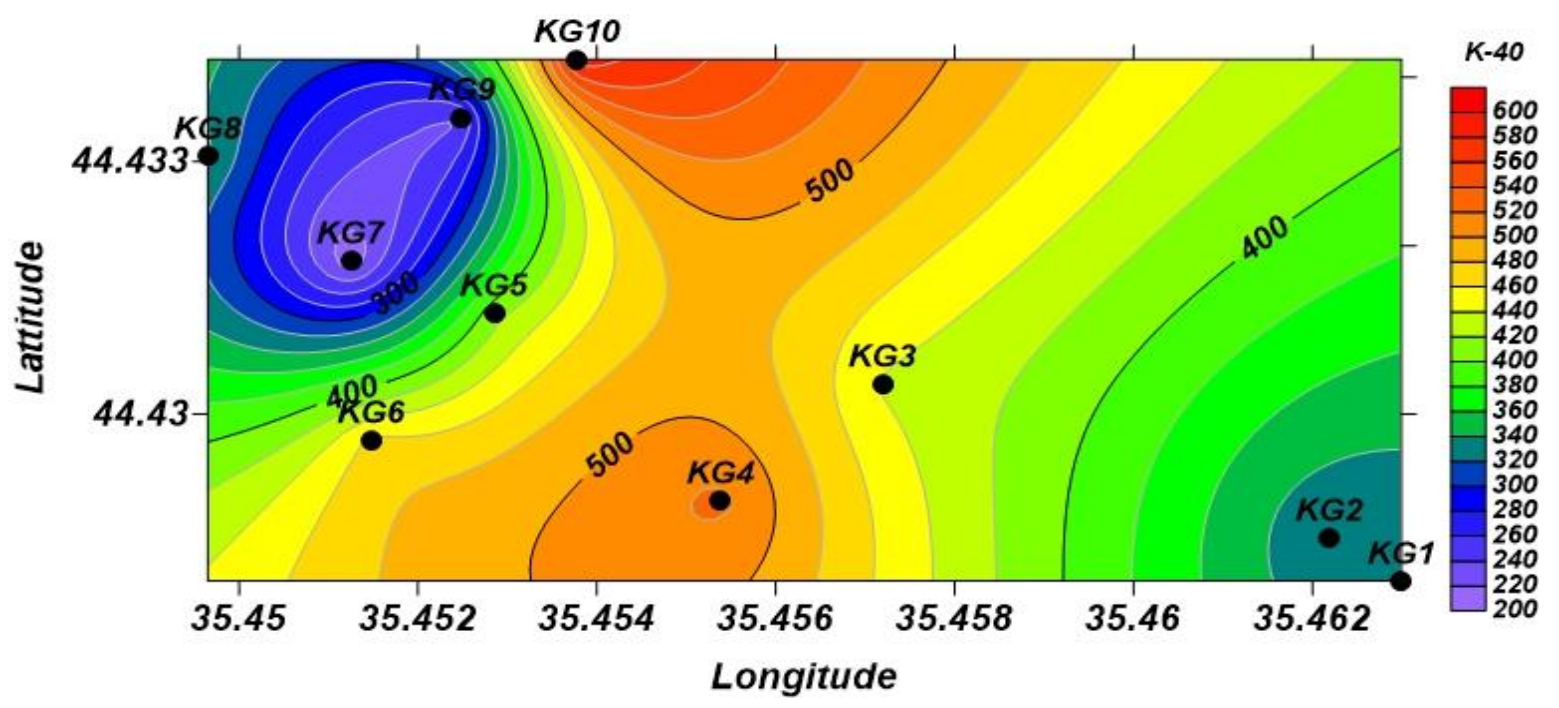

Fig. (7): a contour map of the sample locations and how the specific activity of ${ }^{40} \mathrm{~K}$ are distributed

The measured specific activities of the investigated soil samples are compared with those of the previous studies as presented in Table (2). The specific activities of ${ }^{226} \mathrm{Ra}$ and ${ }^{232} \mathrm{Th}$ reported in previous studies [16], [17] and [18] were higher than the values of the present study. The maximum value of ${ }^{40} \mathrm{~K}$ activity in the present study is much lower than those reported in earlier publications [10], [17], [16], [18], [19], [20], [21] and [22]. The high recorded values of the radionuclides in some soil samples are attributed to the geochemical composition and the samples were collected from the areas around the oil wells.

The obtained radiological hazard indices are illustrated in Table (3). The value of $\mathrm{Ra}_{\mathrm{eq}}$ varied from $66.68-134.49 \mathrm{~Bq} \mathrm{~kg}^{-1}$ with an average value of 107.61 $\mathrm{Bq} \mathrm{kg}^{-1}$. The $\mathrm{D}$ values varies from 32.16 to $67.77 \mathrm{nGy} \mathrm{h}^{-1}$ with an average value of $50.84 \mathrm{nGy} \mathrm{h}^{-1}$.

The range of the calculated $\mathrm{H}_{\mathrm{ex}}$ was $0.18-0.39$ with an average value of 0.29 , where the average value is less than 1. The $H_{\text {in }}$ ranged between 0.25 and 0.57 with an average value less than 1 .

The range of the calculated $\mathrm{I}_{\gamma}$ values was 0.50 to1.04 with an average 0.79 . The $\mathrm{I}_{\gamma}$ values for the studied soil samples have higher values than the world average for the samples KG4 and KG10.

The calculated AEDE values in the present study are listed in Table (3). The results of outdoor effective dose were $0.04-0.08 \mathrm{mSv}^{-1}$ with an average value $0.06 \mathrm{mSv}$ $\mathrm{y}^{-1}$. The results of indoor effective dose were 0.16-0.33 $\mathrm{mSv} \mathrm{y}^{-1}$ with an average value of $0.25 \mathrm{mSv} \mathrm{y}^{-1}$ where the worldwide average values of 0.08 and $0.42 \mathrm{mSv}^{-1}$ [10]. It appears from all the samples that they reached outdoor and indoor (AEDE) less than the Worldwide value

The range of the ELCR values was $0.16 \times 10^{-3}-0.33$ $\times 10^{-3}$, where a mean value $0.25 \times 10^{-3}$ is higher than the world average value $0.29 \times 10^{-3}[10]$. 
Table (2): Range of the specific activity $\left(\mathrm{Bq} \mathrm{kg}^{-1}\right)$ of the selected samples in comparison with previous studies

\begin{tabular}{ccccc}
\hline Country & ${ }^{226} \mathrm{Ra}$ & ${ }^{232} \mathrm{Th}$ & ${ }^{40} \mathrm{~K}$ & References \\
\hline Iraq & $21.01-63.33$ & $16.65-42.95$ & $245.05-798.52$ & {$[19]$} \\
Iraq & $18.40-312.80$ & $9.40-140.80$ & $66.40-800.80$ & {$[16]$} \\
Iraq & $18.56-62.53$ & $15.31-25.88$ & $403.12-684.32$ & {$[20]$} \\
Egypt & $4.00-48.00$ & $8.00-50.00$ & $16.00-487.00$ & {$[22]$} \\
Nigeria & $54.50-94.20$ & $33.30-71.20$ & $462.10-712.40$ & {$[21]$} \\
Pakistan & $21.37-110.51$ & $11.65-172.06$ & $173.96-825.43$ & {$[17]$} \\
Iran & $8.00-55.00$ & $5.00-42.00$ & $250.00-980.00$ & {$[10]$} \\
USA & $8.00-160.00$ & $4.00-130.00$ & $100.00-700.00$ & {$[18]$} \\
Worldwide Average & 35.00 & 30.00 & 400.00 & {$[10]$} \\
This Study & $24.4-68$ & $11.6-27.2$ & $207.2-591$ & \\
\hline
\end{tabular}

Table (3): Radiological hazard indices of the investigated soil samples

\begin{tabular}{ccccccccc}
\hline $\begin{array}{c}\text { Sample } \\
\text { ID }\end{array}$ & $\begin{array}{c}\mathrm{Ra}_{\mathrm{eq}} \\
\left(\mathrm{Bq} \mathrm{Kg}^{-1}\right)\end{array}$ & $\begin{array}{c}\mathrm{D} \\
\left(\mathrm{nGy} \mathrm{h}^{-1}\right)\end{array}$ & $\mathrm{H}_{\mathrm{ex}}$ & $\mathrm{H}_{\mathrm{in}}$ & $\mathrm{I}_{\gamma}$ & $\mathrm{AEDE}_{\text {out }}\left(\mathrm{mSv}^{-1}\right)$ & $\mathrm{AEDE}_{\text {in }}\left(\mathrm{mSv}^{-1}\right)$ & ELCR $\left(\times 10^{-3}\right)$ \\
\hline KG1 & 66.68 & 32.16 & 0.18 & 0.25 & 0.50 & 0.04 & 0.16 & 0.16 \\
KG2 & 117.47 & 55.22 & 0.32 & 0.50 & 0.84 & 0.07 & 0.27 & 0.27 \\
KG3 & 112.01 & 53.23 & 0.30 & 0.43 & 0.82 & 0.07 & 0.26 & 0.26 \\
KG4 & 142.68 & 67.77 & 0.39 & 0.57 & 1.04 & 0.08 & 0.33 & 0.33 \\
KG5 & 108.79 & 51.08 & 0.29 & 0.39 & 0.80 & 0.06 & 0.25 & 0.25 \\
KG6 & 120.15 & 56.95 & 0.32 & 0.46 & 0.88 & 0.07 & 0.28 & 0.28 \\
KG7 & 83.19 & 38.47 & 0.22 & 0.32 & 0.60 & 0.05 & 0.19 & 0.19 \\
KG8 & 120.97 & 56.45 & 0.33 & 0.48 & 0.87 & 0.07 & 0.28 & 0.28 \\
KG9 & 69.71 & 33.00 & 0.19 & 0.28 & 0.51 & 0.04 & 0.16 & 0.16 \\
KG10 & 134.49 & 64.05 & 0.36 & 0.49 & 1.00 & 0.08 & 0.31 & 0.31 \\
Range & $66.68-$ & $32.16-$ & $0.18-$ & $0.25-$ & $0.50-$ & $0.04-$ & $0.16-$ & $0.16-$ \\
Average & 134.49 & 67.77 & 0.39 & 0.57 & 1.04 & 0.08 & 0.33 & 0.33 \\
World Average & 107.61 & 50.84 & 0.29 & 0.42 & 0.79 & 0.06 & 0.25 & 0.25 \\
\hline
\end{tabular}




\subsection{Multivariate statistical analysis}

In the present work, the statistical analysis has been carried out using the statistics software package SPSS version 23.0 for windows. A box plot describes how the specific activities are spread out, while the Cluster analysis and Pearson correlation aim at clarifying the relationship between the statistical variables [23]. In addition, the Principal Component Analysis (PCA) is used to summarize patterns among variables in multivariate datasets, where it is used to identify patterns in variables and to express data in such a way as to highlight their similarities and differences.

\subsubsection{Basic statistics}

Basic statistical variables: mean, median, kurtosis, deviation, and standard deviation of the parameters were measured and listed in Table (4). kurtosis is a measure of the peak of a real-valued random Variable's probability distribution, compared with the usual distribution, it characterizes the relative peak or flatness of a distribution. Positive kurtosis indicates a relatively peaked distribution. Negative kurtosis indicates a relatively flat distribution. In the present study, the kurtosis of ${ }^{226} \mathrm{Ra} \quad(-0.804),{ }^{232} \mathrm{Th} \quad(-0.743)$ and ${ }^{40} \mathrm{~K}(-0.680)$ were found all the radionuclides to have the negative kurtosis which indicate relatively flat distribution, while positive kurtosis of indicated relatively peaked distribution [24]. The skewness of ${ }^{232} \mathrm{Th}$ was negative $(-0.494)$, while ${ }^{226} \mathrm{Ra}$ and ${ }^{40} \mathrm{~K}$ were positive ( 0.241 and 0.152 , respectively).

\subsubsection{Box plot}

The Box plot of how activity concentration spread out for ${ }^{226} \mathrm{Ra},{ }^{232} \mathrm{Th}$ and ${ }^{40} \mathrm{~K}$ in $\mathrm{Bq} \mathrm{kg}{ }^{-1}$ is given in Fig. (8). The median is near the center of the ${ }^{226} \mathrm{Ra}$ and ${ }^{232} \mathrm{Th}$ box, while the median of the ${ }^{40} \mathrm{~K}$ is closer to the bottom of the box, and the distribution is skewed [25].

\subsubsection{Frequency distribution and Q-Q plot}

The frequency distribution and Quantile-quantile (QQ) plots of the specific activity for ${ }^{226} \mathrm{Ra},{ }^{232} \mathrm{Th}$ and ${ }^{40} \mathrm{~K}$ were analyzed and histograms are given in Fig. (9, 10 and 11 , respectively). The distribution of ${ }^{40} \mathrm{~K},{ }^{226} \mathrm{Ra}$ and ${ }^{232} \mathrm{Th}$ radionuclides appears to be normal (bell shape distribution). The multimodality characteristics shows the complexity of radionuclides in soil samples. The QQ plot is shown in the Figs. (9, 10 and 11), all points lie approximately along the 45-degree reference line; the distributions may be assumed to be normal.
Table (4): Statistical variables of the studied samples

\begin{tabular}{lccc}
\hline Variables & ${ }^{226} \mathrm{Ra}$ & ${ }^{232} \mathrm{Th}$ & ${ }^{40} \mathrm{~K}$ \\
\hline Mean & 46.250 & 22.070 & 387.070 \\
Median & 46.900 & 22.850 & 378.400 \\
Std. Deviation & 14.3986 & 6.6853 & 121.8983 \\
Variance & 207.318 & 44.693 & 14859.191 \\
Skewness & 0.241 & -0.494 & 0.152 \\
Kurtosis & -0.804 & -0.743 & -0.680 \\
Minimum & 24.4 & 11.6 & 207.2 \\
Maximum & 68 & 30.2 & 591 \\
Range & 43.6 & 18.6 & 383.8 \\
\hline
\end{tabular}
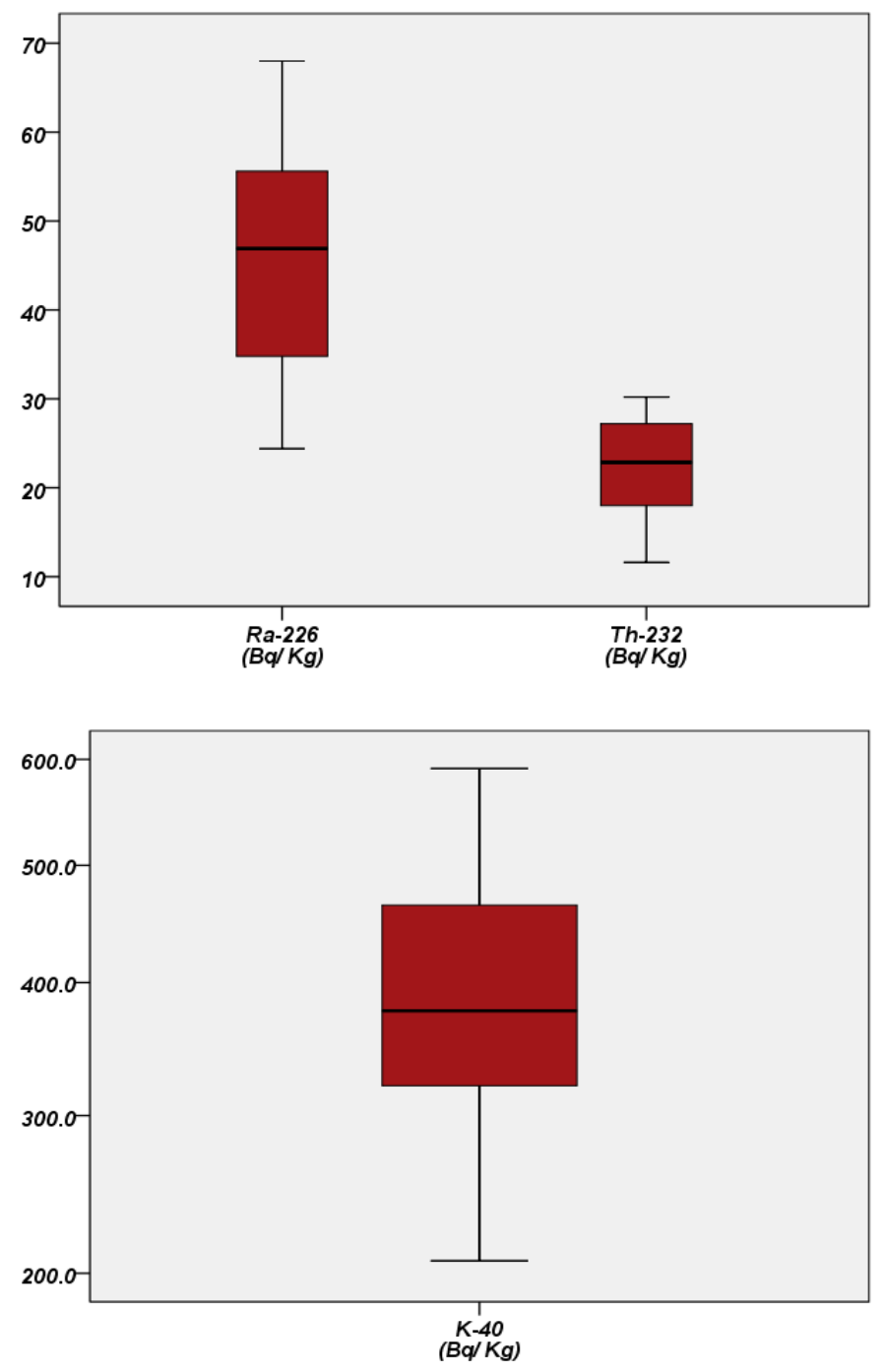

Fig. (8): Box plot of ${ }^{226} \mathrm{Ra},{ }^{232} \mathrm{Th}$ and ${ }^{40} \mathrm{~K}$ of the investigated soil samples 

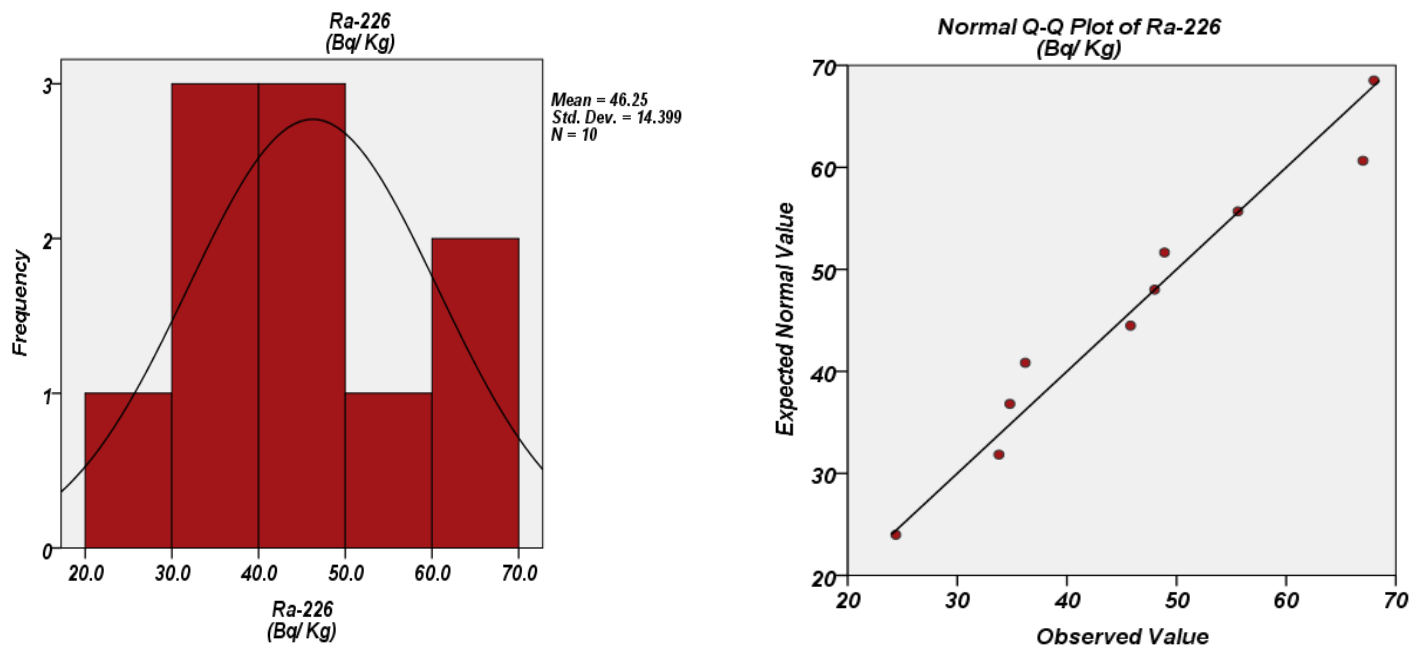

Fig. (9): Frequency distribution and Quantile-quantile (Q-Q) plots of the specific activity for ${ }^{226}$ Ra of the investigated soil samples
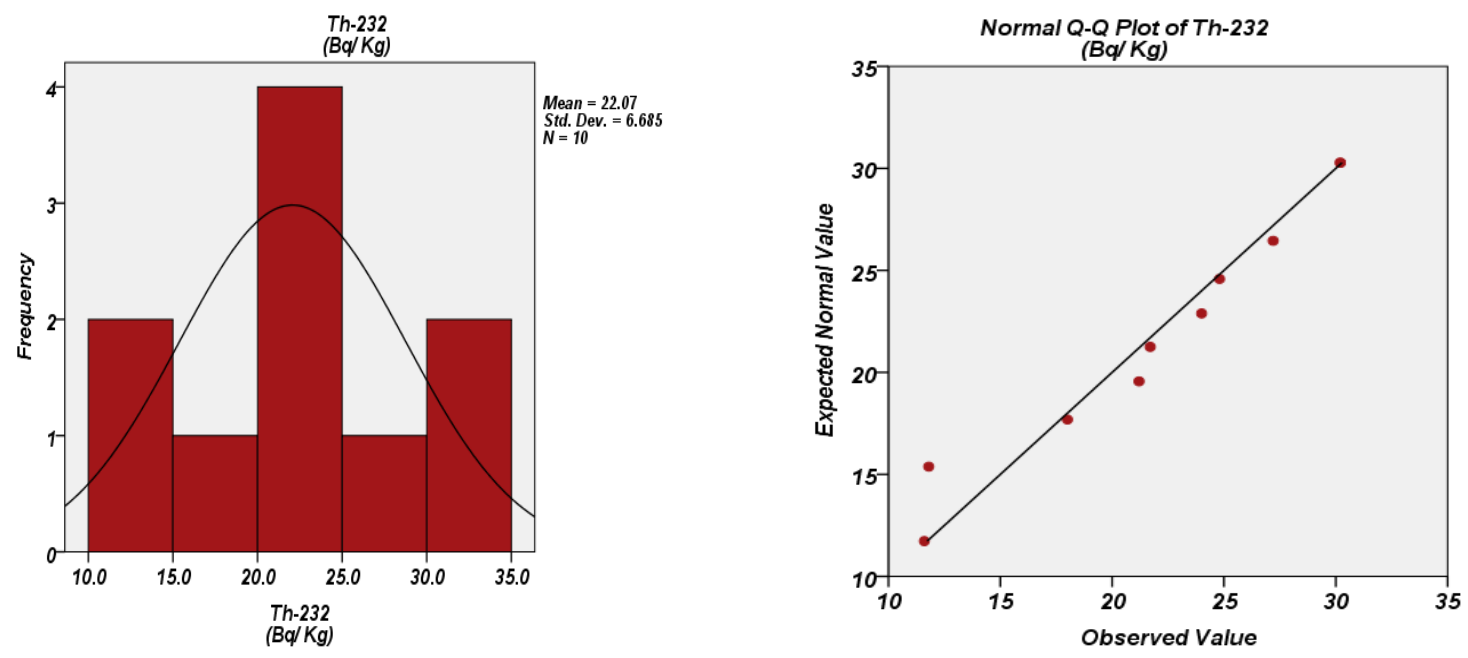

Fig. (10): Same as Fig. 9 for ${ }^{232}$ Th
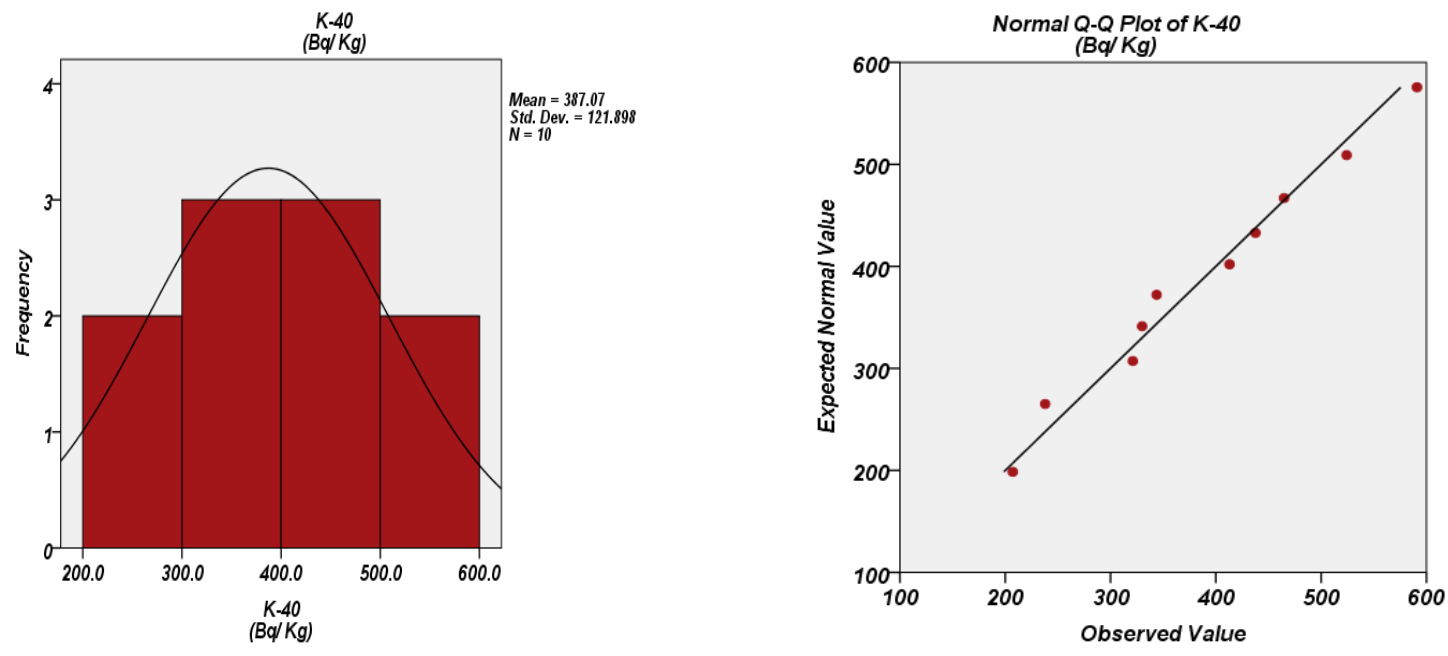

Fig. (11): Same as Fig. 9 for ${ }^{40} \mathrm{~K}$ 


\subsubsection{Pearson's correlation coefficient analysis}

Pearson's correlation coefficient analysis was carried out to determine the mutual relationship and strength between pairs of variables, as shown in Table (5). It was found that ${ }^{232} \mathrm{Th}$ has a weak correlation with ${ }^{226} \mathrm{Ra}$ $(\mathrm{r}=+0.294)$ and the ${ }^{40} \mathrm{~K}$ has a moderate correlation with ${ }^{232} \mathrm{Th}(\mathrm{r}=0.622)$.

\subsubsection{Principal component analyses}

The Principle component analysis (PCA) was applied to identify variables by applying varimax rotation with the Kaiser Normalization Method [26]. The component 1 and component 2 rotation space is illustrated in Table( 6) and Fig. (12), where $49.226 \%$ of the total variance was the first factor, and mainly characterized by high positive loading of ${ }^{226} \mathrm{Ra}$ and ${ }^{40} \mathrm{~K}$ concentrations. The second factor is accounted for $47.024 \%$ of the total variance and mainly consisted of positive loading of ${ }^{232} \mathrm{Th}$. It could be concluded that ${ }^{226} \mathrm{Ra}$ and ${ }^{40} \mathrm{~K}$ dominantly increase the radioactivity in the investigate soil samples

\subsubsection{Cluster analysis}

Cluster Analysis (CA) is used to identify and classify groups with similar features in new observation [25, 27]. The CA was carried out using axes to identify similar characteristics between natural radioisotopes and radiological parameters in soils. In the $\mathrm{CA}$, the average linkage method along with the correlation coefficient distance was applied and the derived dendrogram is shown in Fig.(13) and Table (7) shows the cluster membership, where the variables are grouped in three stages as shown in the Table (7). All the 10 parameters are grouped in four statistically significant clusters. Clusters-I constant of ${ }^{226} \mathrm{Ra}$; cluster II was ${ }^{232} \mathrm{Th}$; cluster III was ${ }^{40} \mathrm{~K}$ and cluster IV consisted of other radiological parameters distribution, which appeared in the same cluster in the first stage. Three clusters were included in the second stage, where the variables of the fourth cluster were merged with the first cluster. In the third stage, the variables of the third cluster were merged with those of the first cluster, thus there are only two clusters, the first and the second. In the last phase, all the cluster were merged with the second cluster.

Table (5): correlation matrix of the studied soil samples

\begin{tabular}{ccccccccccc}
\hline Variables & ${ }^{226} \mathrm{Ra}$ & ${ }^{232} \mathrm{Th}$ & ${ }^{40} \mathrm{~K}$ & $\mathrm{Ra}_{\mathrm{eq}}$ & $\mathrm{D}$ & $\mathrm{H}_{\mathrm{ex}}$ & $\mathrm{H}_{\text {in }}$ & $\mathrm{I}_{\gamma}$ & $\mathrm{AEDE}_{\text {out }}$ & ELCR \\
\hline${ }^{226} \mathrm{Ra}$ & 1 & 0.294 & 0.371 & 0.794 & 0.787 & 0.794 & 0.911 & 0.762 & 0.787 & 0.787 \\
${ }^{232} \mathrm{Th}$ & 0.294 & 1 & 0.622 & 0.753 & 0.741 & 0.753 & 0.619 & 0.761 & 0.741 & 0.741 \\
${ }^{40} \mathrm{~K}$ & 0.371 & 0.622 & 1 & 0.793 & 0.814 & 0.793 & 0.675 & 0.828 & 0.814 & 0.814 \\
$\mathrm{Ra}_{\text {eq }}$ & 0.794 & 0.753 & 0.793 & 1 & 0.999 & 1 & 0.974 & 0.998 & 0.999 & 0.999 \\
$\mathrm{D}$ & 0.787 & 0.741 & 0.814 & 0.999 & 1 & 0.999 & 0.971 & 0.999 & 1 & 1 \\
$\mathrm{H}_{\mathrm{ex}}$ & 0.794 & 0.753 & 0.793 & 1 & 0.999 & 1 & 0.974 & 0.998 & 0.999 & 0.999 \\
$\mathrm{H}_{\text {in }}$ & 0.911 & 0.619 & 0.675 & 0.974 & 0.971 & 0.974 & 1 & 0.961 & 0.971 & 0.971 \\
$\mathrm{I}_{\gamma}$ & 0.762 & 0.761 & 0.828 & 0.998 & 0.999 & 0.998 & 0.961 & 1 & 0.999 & 0.999 \\
$\mathrm{AEDE}_{\text {out }}$ & 0.787 & 0.741 & 0.814 & 0.999 & 1 & 0.999 & 0.971 & 0.999 & 1 & 1 \\
$\mathrm{ELCR}$ & 0.787 & 0.741 & 0.814 & 0.999 & 1 & 0.999 & 0.971 & 0.999 & 1 & 1 \\
\hline
\end{tabular}


Table (6): Rotated factors loading of the variables.

\begin{tabular}{ccc}
\hline \multirow{2}{*}{ Variables } & \multicolumn{2}{|c}{ Component } \\
\cline { 2 - 3 } & 1 & 2 \\
${ }^{226} \mathrm{Ra}$ & 0.993 & 0.107 \\
${ }^{40} \mathrm{~K}$ & 0.305 & 0.843 \\
${ }^{232} \mathrm{Th}$ & 0.178 & 0.892 \\
$\mathrm{Ra}_{\mathrm{eq}}$ & 0.724 & 0.690 \\
$\mathrm{AEDE}$ & 0.718 & 0.696 \\
$\mathrm{H}_{\mathrm{ex}}$ & 0.724 & 0.690 \\
$\mathrm{H}_{\mathrm{in}}$ & 0.861 & 0.507 \\
$\mathrm{l}_{\gamma}$ & 0.690 & 0.724 \\
$\mathrm{D}$ & 0.718 & 0.696 \\
$\mathrm{ELCR}$ & & 0.696 \\
\hline
\end{tabular}

Table (7): Cluster Membership

\begin{tabular}{c|c|c|c}
\hline \multirow{2}{*}{ Variables } & \multicolumn{3}{|c}{ Cluster Membership } \\
\cline { 2 - 4 } & 4 Clusters & 3 Clusters & 2 Clusters \\
\hline${ }^{226} \mathrm{Ra}$ & 1 & 1 & 1
\end{tabular}

$\begin{array}{llll}{ }^{40} \mathrm{~K} & 3 & 3 & 1\end{array}$

$\begin{array}{llll} & 232 \\ \end{array}$

$\begin{array}{llll}\mathrm{Ra}_{\mathrm{eq}} & 4 & 1 & 1\end{array}$

$\begin{array}{llll}\mathrm{AEDE}_{\text {out }} & 4 & 1 & 1\end{array}$

$\begin{array}{llll}\mathrm{H}_{\mathrm{ex}} & 4 & 1 & 1\end{array}$

$\begin{array}{llll}\mathrm{H}_{\text {in }} & 4 & 1 & 1\end{array}$

$\begin{array}{llll}\mathrm{I}_{\gamma} & 4 & 1 & 1\end{array}$

$\begin{array}{llll}\mathrm{D} & 4 & 1 & 1\end{array}$

$\begin{array}{llll}\text { ELCR } & 4 & 1 & 1\end{array}$

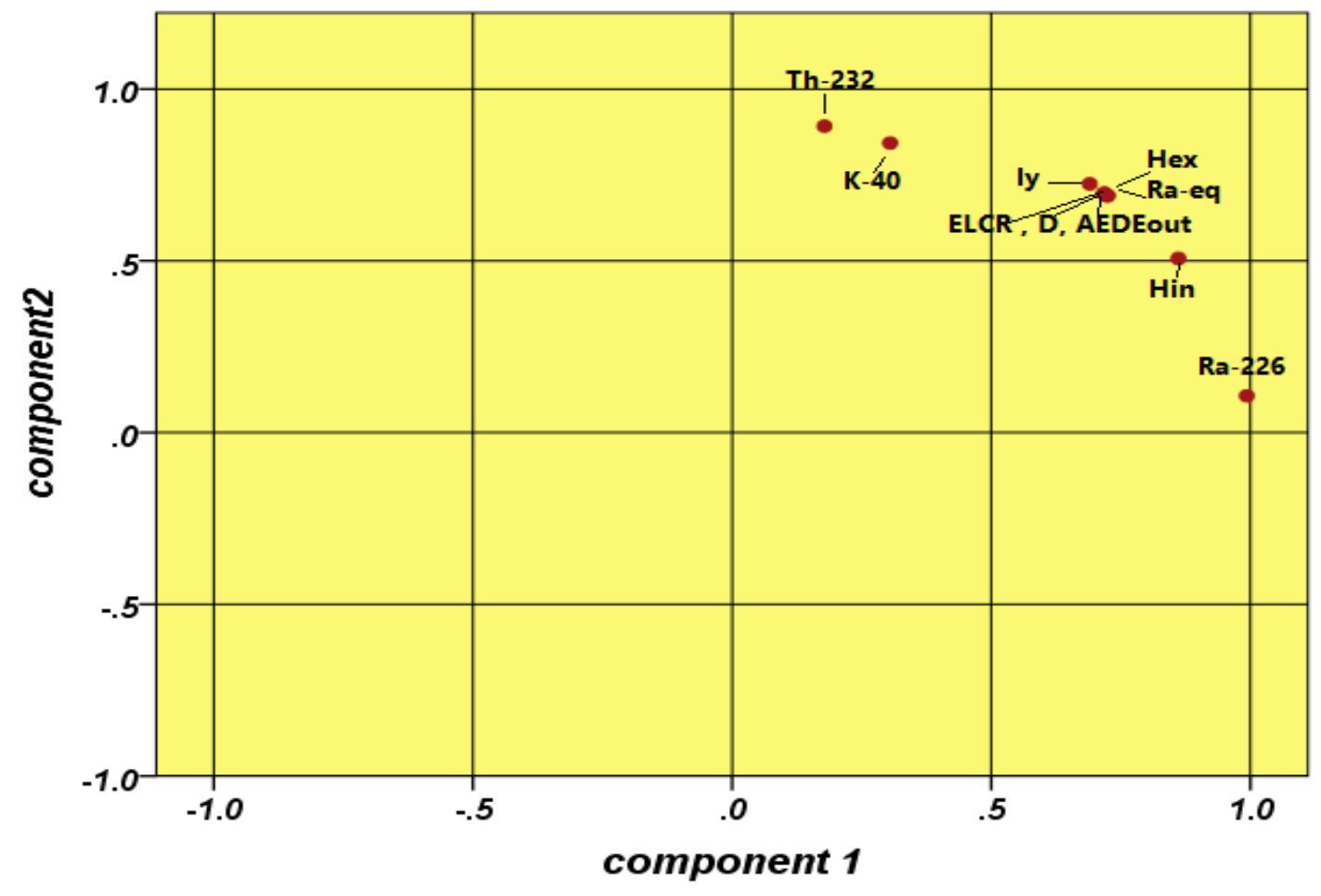

Fig. (12): Graphical representation of Components 1 and 2 


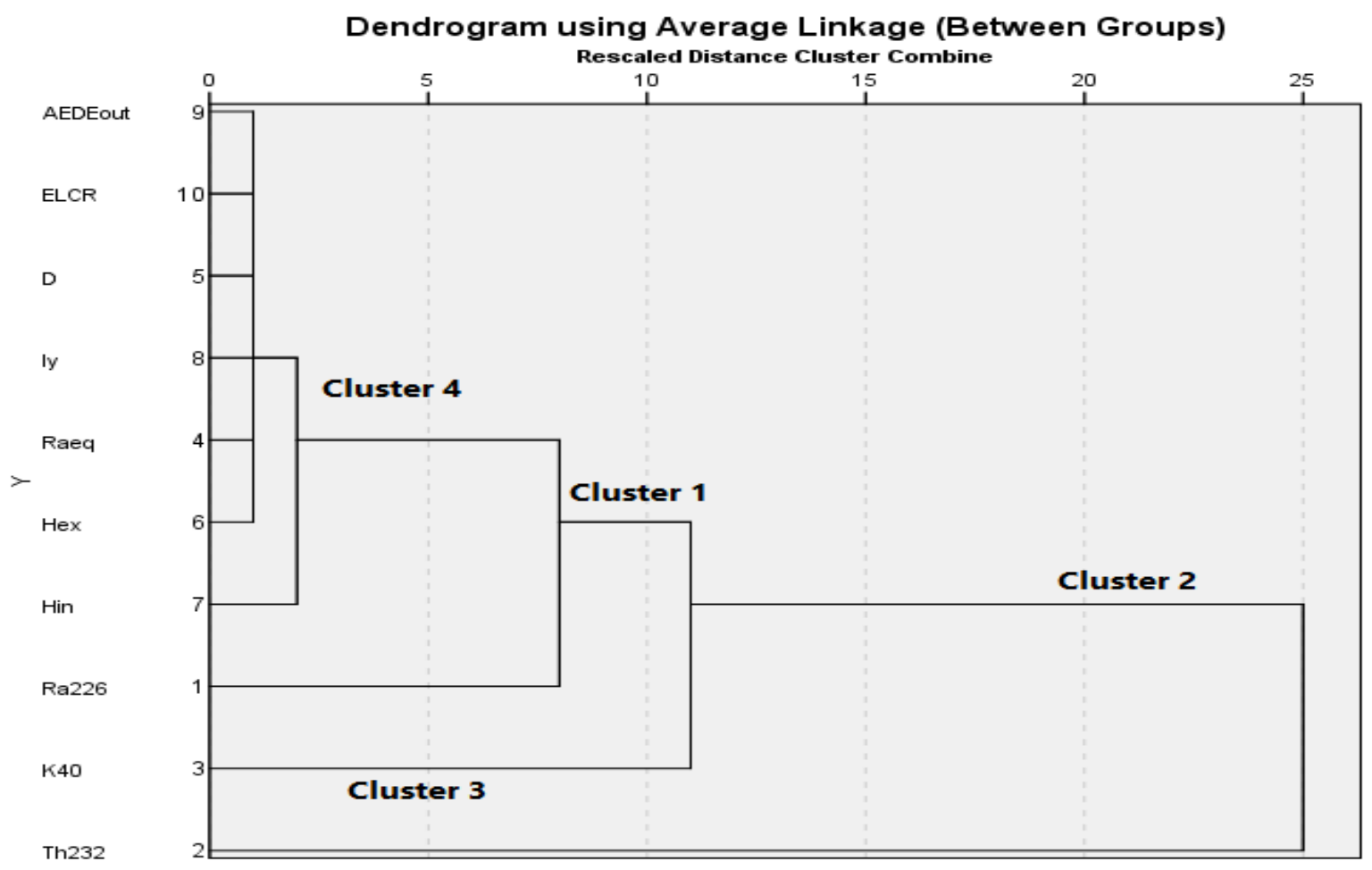

Fig. (13): clustering of radiological parameters

\section{CONCLUSION}

The measured specific activity of ${ }^{40} \mathrm{~K}$ is higher than that of both ${ }^{226} \mathrm{Ra}$ and ${ }^{223} \mathrm{Th}$. This indicates that ${ }^{40} \mathrm{~K}$ is a more abundant than the other radioactive elements of the studied soils. In general, the specific activity of many samples was higher than the recommended worldwide values, because the samples were collected from around oil wells. The average values of the radium equivalent activity $\left(\mathrm{Ra}_{\mathrm{eq}}\right)$ are lower than the international recommended maximum value $\left(370 \mathrm{~Bq} \mathrm{~kg}^{-1}\right)$. The absorbed gamma dose rate is higher than the world average value. The results of the outdoor effective dose were 0.04 to $0.08 \mathrm{mSv} \mathrm{y}^{-1}$ with an average value 0.06 $\mathrm{mSv}^{-1}$. The calculated outdoor effective dose has lower values than the world average value $0.08 \mathrm{mSv}^{-1}$ for some locations. The results of indoor effective dose were 0.16 to $0.33 \mathrm{mSv} \mathrm{y}^{-1}$ with an average value $0.25 \mathrm{mSv} \mathrm{y}^{-1}$. The calculated indoor effective dose was less than the world average value $0.42 \mathrm{mSv} \mathrm{y}^{-1}$. The excess lifetime cancer risk of the soil samples varies from $0.16 \times 10^{-3}$ to $0.33 \times 10^{-3}$ with a mean value $0.25 \times 10^{-3}$ to be higher than the world average ELCR value of $0.29 \times 10^{-3}$.

\section{REFERENCES}

[1] M.S. Yasir, A. Ab Majid, R. Yahaya (2007). Study of natural radionuclides and its radiation hazard index in Malaysian building materials. Radio anal. Nucl. Chem, 273, 539-541.
[2] ICRP (1990) Recommendations if the International commission of Radiological Protection. Annals of the ICRP 21, 1-3.

[3] S. V. Bara, Vishal Arora, S. Chinnaesakki, S. J. Sartandel, B.S. Bajwa, R. M. Tripathi, V. D. Puranik (2012). Radiological assessment of natural and fallout radioactivity in the soil of Chamba and Dharamshala areas of Himachal Pradesh, India. Radioanal. Nucl. Chem, 291, 769-776.

[4] A. Kurnaz, B. KüÇükÖmeroğlu, R. Keser, N.T. Okumusoglu, F. Korkmaz, G. Karahan, U. Çevik (2007). Determination of Radioactivity Levels and Hazards of soil and sediment samples in Firtina Valley (Rize, Turkey). Appl. Radiat. Isotopes, 65, 1281-1289.

[5] Quindos L.S., Fernandez P.L., Soto J., Rodenas C. and Comez (1994), J. Natural Radioactivity in Spanish Soils, Health Physics 66, 196-200.

[6] Akôzcan S, Külahci F, Mercan Y (2018). A suggestion to radiological hazards characterization of ${ }^{226} \mathrm{Ra},{ }^{223} \mathrm{Th},{ }^{40} \mathrm{~K}$ and ${ }^{137} \mathrm{Cs}$. spatial distribution modelling. J Hazard Mater 353, 476489.

[7] Beretka J, Mathew P. J (1995). Natural radioactivity of Australian building materials, industrial wastes and byproducts. Health Phys 48, 87-95. 
[8] Ali H. Taqi, A.M. Shaker, A. A. Battawy (2018). Natural radioactivity assessment in soil samples from Kirkuk city of Iraq using HPGe detector. International Journal of Radiation Research, 16(4), 455-463.

[9] Ali H. Taqi, A. M. Shaker, A. A. Battawy (2018). Natural radioactivity in Building Materials from Kirkuk city of Iraq. Journal of Radiation and Nuclear Application, 3(3), 199-203.

[10] UNSCEAR (2000) Sources and effects of ionizing radiation. In United Nations Scientific Committee on the effect of atomic radiation, U.N., NY (ed). New York.

[11] Zalina Laili, Mohd Zaidi Ibrahim, Nur Azna Mahmud and Muhamat Omar (2012). Natural Radioactivity Content and Radionuclides Lechability of Bricks Containing Industrial Waste, Agensi Nuklear Malaysia, 26-28.

[12] Nur Nazihah Hassan, Kok Siong Khoo (2014). Measurement of Natural Radioactivity and Assessment of Radiation Hazard Indices in Soil Samples at Pengerang, Kota Tinggi, Johor, Aip Conference Proceedings 1584,190; https:// doi.org/10.1063/1.4866130.

[13] Taskin H, Karavus M, Ay P, Topuzoglu A, Hindiroglu S, Karahan G (2009). Radionuclide concentrations in soil and lifetime cancer risk due to gamma radioactivity in Kirklareli, Turkey. J Environ Radioact 100(1): 49-53.

[14] Kolo M. T., Amin Y. M. , Khandaker M. U., Abdullah W. H. B. (2017). Radionuclide concentration and excess lifetime cancer risk due to gamma radioactivity in tailing enriched soil around Maigannga coal mine, Northeast Nigeria. International Journal of Radiation Research 15(1), 71.

[15] ICRP (2007). The 2007 recommendations of the International Commission on Radiological Protection. ICRP publication 103, Ann. ICRP 37, 1-332.

[16] Kamal K. Ali, Shafik Sh. Shafik, Husain A. Husain (2017). Radiological Assessment of NORM Resulting from Oil and Gas Production Processing in South Rumaila Oil Field, Southern Iraq. Iraq Journal of Science 58(2c), 1037-1050.

[17] Qureshi AA, Tariq S, Din KU, Manzoor S, Calligaris C, Wahhed A (2014). Evaluation of excessive lifetime cancer risk due to natural radioactivity in the rivers sediments of Northern Pakistan. J Radiat Res Appl Sci 7(4), 438-447.

[18] Myrick TE, Berven BA, Haywood FF (1983). Determination of concentrations of selected radionuclides in surface soil in the U.S. Health phys, 45, 631-642.

[19] Ali H. Taqi, Laith Abdul Aziz Al-Ani, Abbas M. Ali (2017). Estimating the natural and artificial radioactivity in soil samples from some oil sites in Kirkuk-Iraq using high resolution gamma ray's spectrometry. Indian journal of Pure and Applied physic, 55, 674-682.

[20] Hadi Al-Baidhani, Kadir GUNOGLU and Iskender AKKURT. (2019). Natural Radiation Measurement in Some Soil Sample from Basra oil field IRAQ State.

[21] Agbalagba, E.O., Avwiri, G.O. and Ononugbo, C.P (2013). Evaluation of naturally occurring radioactivity materials (NORM) of soil and sediments in oil and gas wells in western Niger delta region of Nigeria. Environ. Earth Sci. 70, 26132622.

[22] Ibraheim N. M., Shawky S., Amer HA (1995). Radioactivity levels in Lake Nasser sediments. Appl Radiat Isot 46(5), 297-299.

[23] Facchinelli A., Sacchi, E., \& Mallen, L (2001). Multivariate statistical GIS-based approach to identify heavy metal sources in soils. Environmental Pollution, 114, 313-324.

[24] A. M. A. Adam, M. A. H. Eltayeb (2012), Multivariate statistical analysis of radioactive variables in two phosphate ores from Sudan. J Environ Radioactivity, 107, 23-43.

[25] Selin Özden (2021), Natural radioactivity measurements and evaluation of radiological hazards in sediment of Aliağa Bay, Izmir (Turkey).

[26] Suresh Gandhi M, Ravisankar R, Ravisankar R, Rajalakshmi A, Sivakumar S, Chandrasekaran A, Peram Anand D (2014). Measurements of natural gamma radiation in beach sediment of north east coast of Tamilnadu, India by gamma ray spectrometry with multivariate statistical approach. J Radiat Res Appl Sci, 7(1), 7-17.

[27] R Ravisankar, A. Chandrasekaran, Suganath Sivakumar, Prem Anand (2014). Measurement of Natural Radioactivity and Evaluation of Radiation Hazards in Coastal Sediments of East Coast of Tamilnadu using Statistical Approach. 